\title{
Reactive Trace Species in the Boundary Layer from a Micrometeorological Perspective
}

\author{
By D. H. Lenschow \\ National Center for Atmospheric Research* \\ Boulder, Colorado 80307 \\ (Manuscript received 3 October 1981)
}

\begin{abstract}
Mean and turbulence variables of reactive trace species in the atmospheric boundary layer can be modified by chemical reactions. These effects are illustrated with results obtained from an aircraft instrumented with a fast-response ozone sensor. The ozone variance budget was estimated for one case in which production of variance by chemical reactions seems probable. Another example shows thin laminae of ozone concentration considerably different from adjacent layers in the turbulent inversion layer at the top of the boundary layer. Again, chemical reactions seem the most plausible explanation. Vertical profiles of reactive species may also be modified in the surface layer if their reaction time is of the order of a hundred seconds. These effects of chemical reactions may be useful in studying sources and sinks of trace species in the boundary layer.
\end{abstract}

\section{Introduction}

In the past decade, our understanding of the horizontally homogeneous atmospheric boundary layer has improved considerably. We now have a good understanding of the mean and second moment budgets and spectral properties of the air velocity components, temperature and humidity in the convective boundary layer. This has come about largely through the results of several field programs, involving both surfacebased and aircraft measurements, that have been conducted during the past 15 years.

A major factor in the success of these experiments was the utilization of improved observational tools. These include improved sensors such as sonic anemometers and precision thermometers, inertial navigation systems for providing a stable reference on aircraft, and more effective techniques for coping with the large data sets required for utilizing turbulence measurements. Improvements continue to occur. One area currently being pursued is the development of fastresponse sensors for measuring trace gases in the

* The National Center for Atmospheric Research is sponsored by the National Science Foundation. atmosphere. One objective is to be able to resolve the turbulent fluctuations in gas concentration that are important in transporting the species from one level to another in the boundary layer. The instantaneous product of the gas concentration and the vertical velocity, averaged over a sufficiently long time or path length to give a stable estimate, is a direct measure of the vertical flux of that constituent. Microwave and lyman- $\alpha$ sensors for water vapor, and infrared sensors for both water vapor and carbon dioxide (Dobson, et al., 1980) have been developed with sufficient bandwidth $(\sim 10 \mathrm{~Hz})$ that they can be used for flux measurements by this "eddy correlation" technique.

More recently, fast-response sensors have been developed for measuring ozone (Pearson and Stedman, 1980). Thus, we now have the capability of measuring turbulent fluctuations of a reactive trace constituent. Fast-response sensors for other reactive species are likely to be developed soon. The impetus for this is the increasing interest in problems related to sources, sinks, transport and interactions of anthropogenically-generated trace species, many of which are chemically active. Until now, our understanding of the distribution of these species has been 
based almost solely on mean measurements. Yet, the boundary layer is a turbulent medium. Turbulent interactions cannot be ignored in studying the cycles of trace species.

The mean and higher moment budgets of reactive species contain additional terms compared to nonreactive constituents which complicate their analysis. However, proper interpretation of the results can further our understanding of the chemistry of these species, as well as the dynamics of the boundary layer and its interactions with the overlying free atmosphere. In this paper, we discuss the application of micrometeorological techniques to problems of reactive species using, as examples, results from experiments with a well-instrumented aircraft equipped with a fastresponse ozone sensor.

\section{Mean budget and profiles}

The mean budget of a reactive gas $s$, assuming horizontal homogeneity for the flux terms, can be written as

$$
\frac{\partial \bar{s}}{\partial t}=-\frac{\partial \overline{w^{\prime} s^{\prime}}}{\partial z}-\bar{u} \frac{\partial \bar{s}}{\partial x}-\bar{w} \frac{\partial \bar{s}}{\partial z}+\bar{Q}_{s},
$$

where the $x$-axis is chosen to be along the direction of the mean horizontal wind $\bar{u}, \bar{w}$ is the mean vertical velocity, positive upwards in the $z$ direction, and $\bar{Q}_{s}$ is the internal sources and sinks of $\bar{s}$. The overbar denotes an average over a distance, or time, long enough to ensure a stable estimate of the variable, and the prime denotes an instantaneous departure from the mean. First-order chemical reaction terms in $Q_{s}$ are proportional to the concentration of the reacting species, while second-order reactions are proportional to the concentration of both reacting species. The mean vertical velocity term can usually be neglected, so that (1) reduces to

$$
\frac{\partial \bar{s}}{\partial t}+\frac{\partial \overline{w^{\prime} s^{\prime}}}{\partial z}+\bar{u} \frac{\partial \bar{s}}{\partial x}=\bar{Q}_{s} .
$$

Thus, if the vertical turbulent flux divergence, the mean rate of change with time and the horizontal advection are measured, the internal source or sink of $\bar{s}$ can be determined. This has been done by Lenschow et al. (1981) for ozone in a daytime convective boundary layer, where they observed significant photochemical production of ozone. Therefore, we use ozone as an example in the following discussion, although other reactive species could also be considered.

The major short-term variations in ozone concentration result from the reactions (Chameides,
1978)

$$
\begin{aligned}
& \mathrm{NO}_{2}+h \nu \rightarrow \mathrm{NO}+\mathrm{O} \\
& \mathrm{O}_{2}+\mathrm{O}+\mathrm{M} \rightarrow \mathrm{O}_{3}+\mathrm{M} \\
& \mathrm{NO}+\mathrm{O}_{3} \rightarrow \mathrm{NO}_{2}+\mathrm{O}_{2} .
\end{aligned}
$$

This sequence of reactions does not permanently generate or destroy $\mathrm{NO}_{2}, \mathrm{NO}$ and $\mathrm{O}_{3}$, but rather allows the molecules to be interchanged, depending upon the radiation intensity in (3). Reaction (4) is sufficiently fast that (3) and (4) can be combined so that, neglecting other slower reactions involving these species,

$$
Q_{s}=k_{1}\left(\mathrm{NO}_{2}\right)-k_{2}(\mathrm{NO})\left(\mathrm{O}_{3}\right)
$$

and (2) becomes

$$
\begin{aligned}
& \frac{\partial \overline{\mathrm{O}_{3}}}{\partial t}+\frac{\partial \overline{w^{\prime} \mathrm{O}_{3}{ }^{\prime}}}{\partial z}+\bar{u} \frac{\partial \overline{\mathrm{O}_{3}}}{\partial x} \\
& =k_{1} \overline{\mathrm{NO}_{2}}-k_{2} \overline{\mathrm{NO}} \overline{\mathrm{O}_{3}}+\overline{(\mathrm{NO})^{\prime}\left(\mathrm{O}_{3}\right)^{\prime}},
\end{aligned}
$$

where $k_{1}$ and $k_{2}$ are the reaction coefficients of (3) and (5), respectively. In the absence of other competing reactions, rapid light intensity changes and concentration fluctuations, $\bar{Q}_{s}=0$ (Leighton, 1961). For these limiting conditions,

$$
k_{1} \overline{\mathrm{NO}_{2}}=k_{2} \overline{\mathrm{NO}} \overline{\mathrm{O}_{3}} \text {. }
$$

We note that $\mathrm{O}_{3}$ in (6) can be replaced with $\mathrm{NO}$ or $-\left(\mathrm{NO}_{2}\right)$ if no other internal sources or sinks for these species exist. Thus, we have a set of three equations which, in principle, can be solved for the mean concentrations if the budget terms on the left side and the covariance term on the right side of (6) can be estimated.

As an example of the effects of chemical reactions, we investigate the mean concentration profiles in the surface layer. Reactive species such as $\mathrm{O}_{3}$ and $\mathrm{NO}_{2}$ are absorbed at the earth's surface, which produces a positive gradient of the species near the surface. This means that even if these species are in the photostationary state well above the surface, they may not be within the surface layer. Thus, chemical reactions may occur within the surface layer that can modify the mean concentration profiles. This may have to be taken into account if, for example, the profile method of estimating flux is being used. Significant departures from expected mixed-layer ozone profiles have previously been noted by van Dop et al. (1977). They observed a maximum in ozone concentration at about $500 \mathrm{~m}$ height (well below the top of the mixed layer) which was sometimes several times the observed concentration near the ground.

We can estimate a characteristic time for the 
reactions to occur and compare this with a characteristic diffusion time in the surface layer to see whether significant profile modifications are likely to occur. We consider just the source/ sink term $Q_{s}$ and neglect the left side and the covariance term on the right side of (6):

$$
\bar{Q}_{s}=\frac{d \overline{\mathrm{O}_{3}}}{d t}=k_{1}\left(\overline{\mathrm{NO}_{2}}\right)-k_{2}(\overline{\mathrm{NO}})\left(\overline{\mathrm{O}}_{3} \overline{)} .\right.
$$

If we assume that no other chemical reactions occur that generate or destroy these species, the solution is

$$
\begin{aligned}
& \overline{\mathrm{O}_{3}}(t)=\alpha k_{2}^{-1} \tanh \left(\alpha t+\tanh ^{-1} \frac{k_{2} \overline{\mathrm{O}_{3}}(0)+C}{\alpha}\right) \\
& -C k_{2}{ }^{-1},
\end{aligned}
$$

where

$$
\begin{aligned}
\alpha= & \frac{1}{2}\left[k_{1}{ }^{2}+k_{2}{ }^{2}\left(\overline{\mathrm{O}_{3}}-\overline{\mathrm{NO}}\right)^{2}\right. \\
& \left.+2 k_{1} k_{2}\left(\overline{\mathrm{O}_{3}}+\overline{\mathrm{NO}}+2 \overline{\mathrm{NO}_{2}}\right)\right]^{1 / 2}, \\
C= & \frac{1}{2}\left[k_{1}-k_{2}\left(\overline{\mathrm{O}_{3}}-\overline{\mathrm{NO}}\right)\right]
\end{aligned}
$$

and $\overline{\mathrm{O}_{3}}(0)$ is the $\overline{\mathrm{O}_{3}}$ concentration at $t=0$. Since for every molecule of $\mathrm{O}_{3}$ lost, a molecule of NO is also lost and a molecule of $\mathrm{NO}_{2}$ is generated, $\left(\overline{\mathrm{O}_{3}}-\overline{\mathrm{NO}}\right)$ and $\left(\overline{\mathrm{O}_{3}}+\overline{\mathrm{NO}}+2 \overline{\mathrm{NO}_{2}}\right)$ are constant. A typical value of $\overline{\mathrm{O}_{3}}$ is $40 \mathrm{ppb} ; k_{1} \sim 4 \times 10^{-3} \mathrm{~s}^{-1}$ and $k_{2} \sim 0.4 \times 10^{-3}(\mathrm{ppb})^{-1} \mathrm{~s}^{-1}$ (Chameides and Stedman, 1977). In pristine or slightly polluted air, $\overline{\mathrm{O}_{3}} \gg \overline{\mathrm{NO}}+\overline{\mathrm{NO}_{2}}$. Thus, the characteristic time scale for this set of chemical reactions is $\alpha^{-1} \sim$ $100 \mathrm{~s}$.

In the surface layer, the characteristic diffusion time scale is $\sim z /\left(u_{* k}\right)$, where $u_{*} \equiv\left(-\overline{u^{\prime} w^{\prime}}\right)_{0}{ }^{1 / 2}$ is the friction velocity and $\kappa$ is the von Karman constant taken as 0.35 . For a typical value of $u_{*}=0.3 \mathrm{~m} \mathrm{~s}^{-1}$, we see that the time scales are about equal at $z \sim 10 \mathrm{~m}$. Thus, it seems likely that surface layer profiles can be modified for $\mathrm{O}_{3}$, NO and $\mathrm{NO}_{2}$ if the sources or sinks at the surface significantly perturb the photostationary state. Furthermore, we can show that the reaction rates for this set of reactions is the same order of magnitude as the time required to diffuse a concentrated source out to a distant of several hundred meters. From the results of Lamb and Durran (1978) we estimate that the vertical eddy diffusivity throughout most of the convective boundary layer is given by $K_{z} \sim 0.2$ $w_{*} z_{i}$, where $w_{*} \equiv\left(H z_{i}\right)^{1 / 3}$ is the convective velocity scale, $z_{i}$ is the height of the boundary layer and $H$ is turbulent energy production by buoyancy at the surface. $\left[H \equiv\left(g / \bar{\theta}_{v}\right)\left(\overline{w^{\prime} \theta_{v}{ }^{\prime}}\right)_{0}\right.$ where $\theta_{v}$ is the virtual potential temperature and $g$ is gravitational acceleration.] A characteristic length scale $l$ for diffusion from a concentrated source is given by $l \sim \sqrt{K_{z} t}$. For typical values of $w_{*}=$ $1.5 \mathrm{~m} \mathrm{~s}^{-1}, z_{i}=1,500 \mathrm{~m}$, and $t=100 \mathrm{~s}$ we have $l \sim 200 \mathrm{~m}$. Therefore, we can expect that significant chemical reactions can occur at length scales that are important for turbulence processes in the boundary layer.

Since we have shown that chemical reactions can modify the concentration profiles in the surface layer, we show how the modified profiles can be calculated. For this discussion, we neglect the covariance term on the right side of (6). Although the magnitude of this term is considerably smaller than either of the other two terms on the right side of (6), it is not necessarily always smaller than their difference.

From similarity theory, the flux-profile relation is

$$
\frac{\partial \bar{s}}{\partial z}=-\frac{\overline{w^{\prime} s^{\prime}}}{\kappa u_{*} z} \phi_{s}(z / L),
$$

where $\phi_{s}$ is a function of the stability parameter $z / L$, and the Obukhov length $L \equiv-u_{*}{ }^{3} /{ }_{k} H$. We have assumed here that (7) is applicable not only for constant surface layer flux, but also for variable flux of a reactive trace constituent in the surface layer. This is equivalent to assuming that the similarity hypothesis can be used to determine the ratio of the flux to the gradient (i.e. an eddy transfer coefficient) and that this coefficient is independent of the flux variations in the surface layer. A discussion of similarity concepts and formulations for $\phi_{S}$, where $s$ is replaced by $u$ and by potential temperature $\theta$, is given by Businger (1973).

Substituting (7) into (6) and assuming steadystate and negligible horizontal advection

$$
\kappa u_{*} \frac{\partial}{\partial z}\left(\phi_{s^{-1}} z \frac{\partial \overline{\mathrm{O}_{3}}}{\partial z}\right)+k_{1} \overline{\mathrm{NO}_{2}}-k_{2} \overline{\mathrm{NO}} \overline{\mathrm{O}_{3}}=0 .
$$

Similarly, since $\left(\overline{\mathrm{O}_{3}}-\overline{\mathrm{NO}}\right)$ and $\left(\overline{\mathrm{O}_{3}}+\overline{\mathrm{NO}_{2}}\right)$ are constant, $\overline{\mathrm{NO}}$ and $\overline{\mathrm{NO}_{2}}$ follow the relations

$$
\begin{aligned}
& \kappa u_{*} \frac{\partial}{\partial z}\left(\phi_{s}^{-1} z \frac{\partial \overline{\mathrm{NO}}}{\partial z}\right)+k_{1} \overline{\mathrm{NO}_{2}}-k_{1} \overline{\mathrm{NO}} \overline{\mathrm{O}_{3}}=0 . \\
& \kappa u_{*} \frac{\partial}{\partial z}\left(\phi_{s}^{-1} z \frac{\partial \overline{\mathrm{NO}_{2}}}{\partial z}\right)-k_{1} \overline{\mathrm{NO}_{2}}+k_{2} \overline{\mathrm{NO}} \overline{\mathrm{O}_{3}}=0 .
\end{aligned}
$$

Eqs. (8), (9) and (10) can be combined to yield 


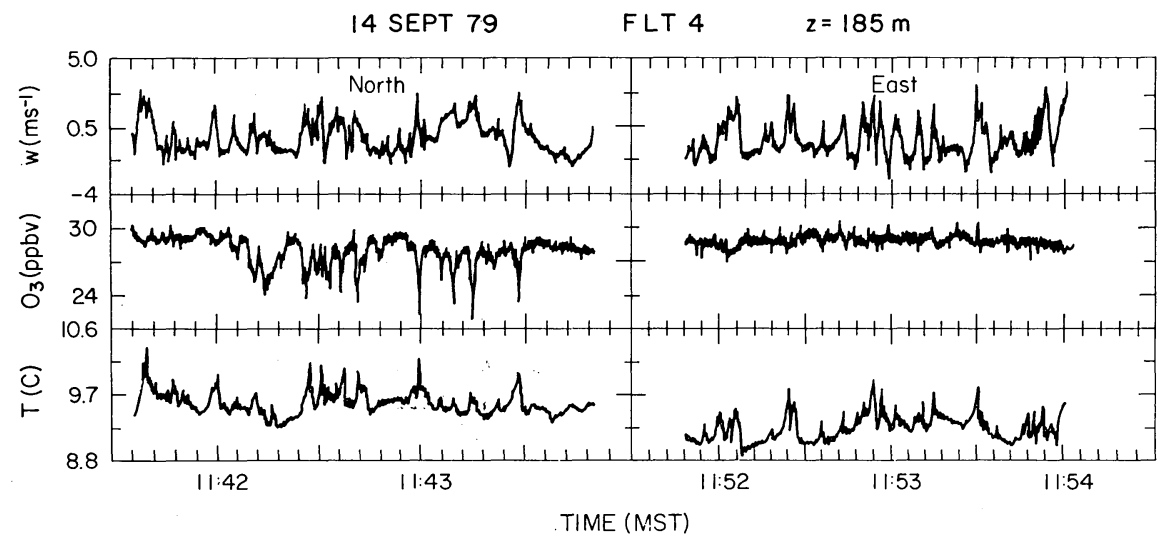

Fig. 1 Time series of vertical velocity, ozone and temperature over mixed farmland and rangeland in northeastern Colorado. The set on the left is in the vicinity of an interstate highway and the set on the right is a flight path directed away from the highway (Lenschow et al., 1981).

$$
\begin{gathered}
\frac{\partial}{\partial z}\left[\phi_{s}^{-1} z\left(\frac{\partial \overline{\mathrm{O}_{3}}}{\partial z}-\frac{\partial \overline{\mathrm{NO}}}{\partial z}\right)\right]=0 \\
\frac{\partial}{\partial z}\left[\phi_{s}^{-1} z\left(\frac{\partial \mathrm{O}_{3}}{\partial z}+\frac{\partial \mathrm{NO}_{2}}{\partial z}\right)\right]=0
\end{gathered}
$$

Eqs. (11) and (12) can be solved for $\overline{\mathrm{NO}}(z)$ and $\overline{\mathrm{NO}_{2}}(z)$ which can then be substituted into (8). Eq. (8) can then be solved for $\overline{\mathrm{O}_{3}}(z)$. The boundary conditions can be specified as the values of the gradients (which determine the surface flux) and the mean values very near the surface for each of the species.

\section{Variance and its budget}

In this section we investigate the effects that chemical reactions may have on the variance and variance budget of a reactive species. Fig. 1 shows that the ozone variance $185 \mathrm{~m}$ above the ground in the vicinity of a highway can be several times larger than over similar terrain away from the highway. This is a result of vehicular emission of NO which removes $\mathrm{O}_{3}$. For this case, the ozone flux was also enhanced by a factor of 2 to 3 . Thus, there is no question that chemical reactions can alter the variances and covariances of reactive species.

We do not yet have sufficient data to construct a variance profile or study the variance budget in a region such as this where obvious enhancement of variance and fluxes due to chemical reactions has occurred. We can, however, analyze a case over northeastern Colorado not immediately downwind of any major source of urban pollution, but within a region where small local sources existed. Four levels (15, 61, 152 and
$305 \mathrm{~m}$ above the surface) were flown over relatively flat mixed rangeland and irrigated farmland from mid- to late morning on a clear September day. The mean ozone budget for this case has already been analyzed (Lenschow et al., 1981) and a production rate of $1.4 \mathrm{ppt} \mathrm{s}^{-1}$ was estimated, which is equivalent to a doubling time of about 8 hours.

As discussed by Lenschow et al. (1981), the ozone sensor output contains Poisson-distributed white noise contributed by the photon counting process. The noise variance, which adds to the signal variance, is proportional to the mean value of the signal, but is uncorrelated with vertical velocity so that the turbulent fluxes are unaffected. We can estimate the noise variance by measuring the variance when the signal variance is expected to be small. Then this measured noise variance can be subtracted from the measured variance to obtain the signal variance.

In evaluating the variance and terms in the variance budget, we use mixed-layer scaling parameters, $z_{i}, w_{*}$ and $s_{*} \equiv\left(\overline{w^{\prime} s^{\prime}}\right)_{0} / w_{*}$ to normalize the terms.

The corrected normalized variances are presented in Fig. 2. The estimated noise variance, which has been subtracted, made up about $60 \%$ of the measured variance. The variance is observed to be almost constant with height. Lenschow et al. (1980b) have shown that temperature and humidity variances follow the local free convection formulation (Wyngaard et al., 1971)

$$
\overline{s^{\prime 2}} / s_{*}^{2}=1.8 z_{*}^{-2 / 3},
$$

where $z_{*}=z / z_{i}$, in the lower $20 \%$ of the mixed 


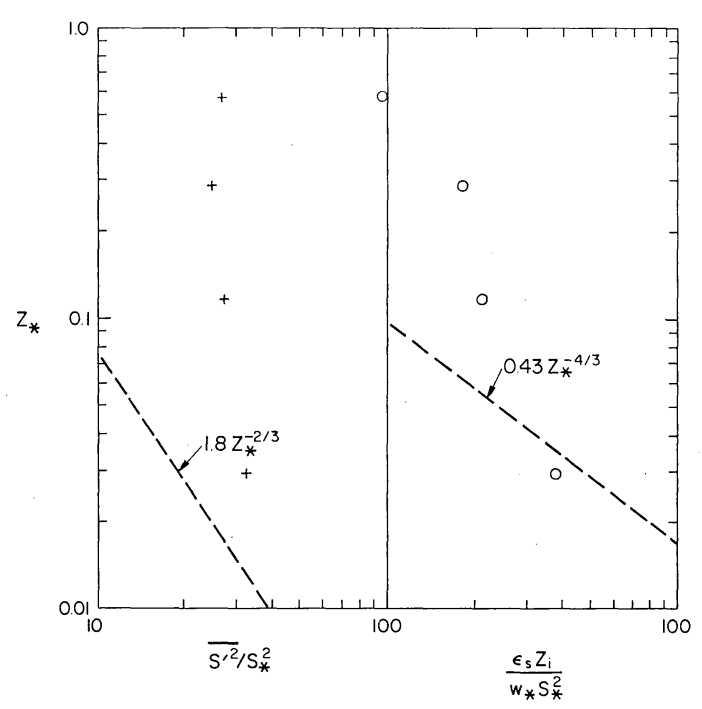

Fig. 2 Normalized variance (left) and variance dissipation rate (right) of ozone in a convective boundary layer plotted as a function of normalized height $\mathrm{z}_{*}=\mathrm{z} / \mathrm{z}_{i}$. Local free convection forms for both variables which have been fit to temperature and humidity data are plotted as dashed lines.

layer. This suggests that ozone variance may be generated by processes other than flux at the surface; i.e., chemical reactions. The evidence is not conclusive, however, since entrainment of air of different ozone concentration at the top of the boundary layer, which is significant for this case (Lenschow et al., 1981), can also generate ozone variance. The temperature and humidity variance profiles of Lenschow et al. (1980b) indicate that the entrainment process, which is not included in the free convection formulation, causes the variance to increase in the upper half of the mixed layer. This process has been parameterized for the structure functions of temperature and humidity by Wyngaard and LeMone (1980).

Further evidence of significant effects on ozone variance by chemical reaction is provided by analysis of the variance budget. The variance budget of a chemically active species is (Lenschow et al., 1980a)

$$
\begin{aligned}
& \frac{1}{2} \frac{\partial \overline{s^{\prime 2}}}{\partial t}=-\overline{w^{\prime} s^{\prime}} \frac{\partial \bar{s}}{\partial z}-\frac{1}{2} \frac{\partial \overline{w^{\prime} s^{\prime 2}}}{\partial z} \\
& -\varepsilon_{s}+\overline{s^{\prime} Q_{s}^{\prime}} \simeq 0
\end{aligned}
$$

where $\varepsilon_{S}$ is the molecular dissipation rate of the variance of $s$. The last term in (14) is the generation of variance by internal sources or sinks of $s$. Variance budgets of nonreactive scalars have been measured previously. Wyngaard and Coté (1971), for example, have published a normalized budget of temperature variance in the surface layer using similarity arguments, and Lenschow et al. (1980b) have estimated most of the terms in the mixed layer variance budgets of temperature and humidity, using mixed layer normalization. Therefore, we can evaluate the budget of a reactive species (such as ozone) and, by comparison with nonreactive scalars, investigate whether $\overline{s^{\prime} Q_{s}{ }^{\prime}}$ makes a significant contribution.

The spectral density of ozone $E_{s}(k)$ in the inertial subrange is used to estimate $\varepsilon_{s}$ by the relation

$$
\varepsilon_{s}=E_{s}(k) \varepsilon^{1 / 3} k^{5 / 3} \beta_{1}{ }^{-1},
$$

where $\beta_{1}$, the spectral constant, is taken to be 0.82 (Champagne et al., 1977), $k$ is the wavenumber, and $\varepsilon$ is the dissipation of turbulence energy by viscous processes. We assume here that chemical reactions do not affect the spectrum in the inertial subrange. Since only the high wavenumber end of the spectrum is used in (15), the effect of sensor noise is more difficult to remove than for variance. Lenschow et al. (1981) show an example of the ozone spectrum for one of the legs. The estimates of $\varepsilon_{s}$ presented in Fig. 2 were obtained by manually fitting a line to the logarithmic plots at the low wavenumber end of the $-5 / 3$ spectral region. The values of $\varepsilon_{s}$ may be overestimated to some extent; nevertheless, the estimated values for $z_{*}>0.1$ are considerably larger than the dashed line in Fig. 2 , which is a reasonable fit to the normalized temperature dissipation observations of Kaimal et al. (1976) and the humidity dissipation observations of Lenschow et al. (1980b) up to $z_{*}=0.1$.

The mean ozone gradient was estimated by a least squares fit to the mean concentration at all four levels after correcting for the time rate of change. The measured value was $3.6 \times 10^{-3}$ $\mathrm{ppb} \mathrm{m}^{-1}$. Multiplying this by the flux at each level, averaging and normalizing, we have

$$
\frac{z_{i}}{w_{*} S_{*}^{2}} \cdot \overline{w^{\prime}} \overline{\mathrm{O}_{3}{ }^{\prime}} \frac{\partial \overline{\mathrm{O}_{3}}}{\partial z} \simeq 12.5 \text {. }
$$

The normalized vertical flux of ozone variance, shown in Fig. 3, decreases less rapidly with height than predicted by the local free-convection form (Wyngaard et al., 1971), which is also shown in Fig. 3. Lenschow et al. (1980b) found that temperature and humidity followed the free- 
convection form up to $z_{*} \simeq 0.2$; above this humidity showed considerable scatter, while temperature decreased more rapidly than the freeconvection predictions.

Summing these three terms we find that the dissipation is considerably larger than the sum of production and transport. Thus, we have additional evidence that the reactive term is significant in the variance equation. Using (6a) and neglecting the third moment term, this term can be written as

$$
\begin{aligned}
& \overline{s^{\prime} Q_{s^{\prime}}}=k_{1} \overline{\left(\mathrm{O}_{3}\right)^{\prime}\left(\mathrm{NO}_{2}\right)^{\prime}} \\
& \quad-k_{2}\left[\overline { \mathrm { O } _ { 3 } } \left(\overline{\left.\mathrm{O}_{3}\right)^{\prime}(\mathrm{NO})^{\prime}}+\overline{\mathrm{NO}}\left(\overline{\left.\mathrm{O}_{3}\right)^{\prime 2}}\right] .\right.\right.
\end{aligned}
$$

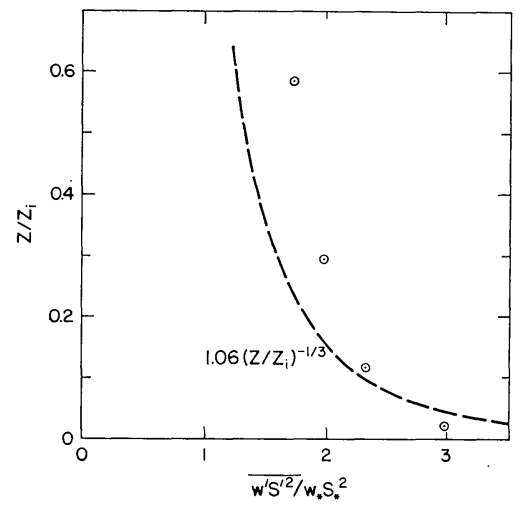

Fig. 3 Normalized vertical transport of ozone variance. The dashed line is the local free convection form which has been fit to temperature and humidity data.
Substituting for the rate coefficients and $\overline{\mathrm{O}_{3}}$, and normalizing,

$$
\begin{gathered}
\frac{z_{i}}{w_{*} s_{*}^{2}} \overline{s^{\prime}} \overline{Q_{s^{\prime}}} \simeq 72\left(\overline{\left.\mathrm{O}_{3}\right)^{\prime}}\left(\overline{\mathrm{NO}_{2}}\right)^{\prime}\right. \\
-325 \overline{\left(\mathrm{O}_{3}\right)^{\prime}(\mathrm{NO})^{\prime}}-4 \overline{\mathrm{NO}},
\end{gathered}
$$

where concentrations are in units of ppb. Since the value of

$$
\bar{Q}_{s}=k_{1} \overline{\mathrm{NO}_{2}}-k_{2}\left[\overline{\mathrm{NO}} \overline{\mathrm{O}_{3}}-\overline{(\mathrm{NO})^{\prime}\left(\mathrm{O}_{3}\right)^{\prime}}\right]
$$

can be estimated from the mean ozone budget, it is possible in principle to solve for $\overline{\left(\mathrm{O}_{3}\right)^{\prime}\left(\mathrm{NO}_{2}\right)^{\prime}}$ and $\overline{\left(\mathrm{O}_{3}\right)^{\prime}(\mathrm{NO})^{\prime}}$ if mean values of $\mathrm{NO}$ and $\mathrm{NO}_{2}$ can also be measured. These covariances may be useful in determining where the sources and sinks of $\mathrm{NO}$ and $\mathrm{NO}_{2}$ are in the boundary layer and in studying the limitations of assuming the photostationary state.

\section{Concentration laminae}

Thus far we have discussed modification in the behavior of trace species due to chemical reactions that are predictable departures from the behavior of nonreactive species. Here we show two examples of very thin layers $(\sim 60 \mathrm{~m}$ thick) in the turbulent inversion layer at the top of the boundary layer (in one case, the previous day's boundary layer) where the ozone concentration is markedly different from its surroundings. These layers illustrate the complications that can occur in studying the mean structure of a reactive

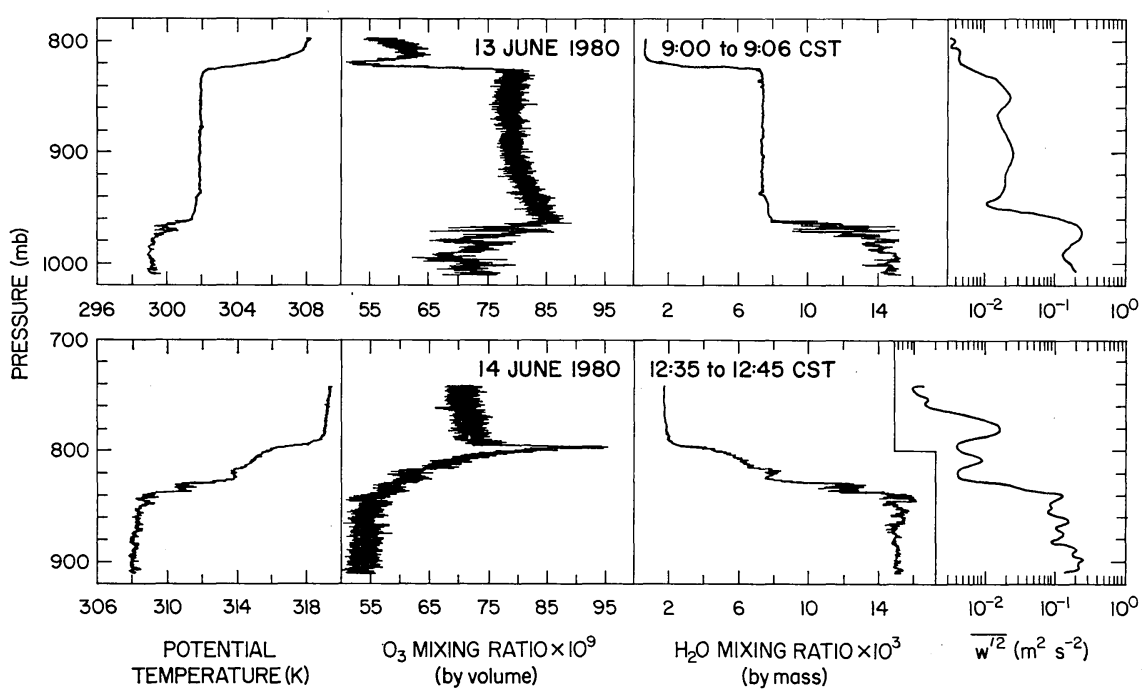

Fig. 4 Vertical aircraft soundings over eastern Texas (top) and southern Nebraska (bottom). The data sample rate was $20 \mathrm{~s}^{-1}$. The vertical velocity variance was obtained by high-pass filtering the vertical velocity at $0.5 \mathrm{~Hz}$, squaring, then smoothing the results with a $0.02 \mathrm{~Hz}$ low-pass filter. The airplane speed was $\sim 65 \mathrm{~ms}^{-1}$. 
species.

Fig. 4 shows two sets of vertical soundings obtained from an aircraft using fast response temperature, humidity, vertical velocity and ozone sensors. The top set, which was obtained about $100 \mathrm{~km}$ northeast of Houston, Texas, is a morning sounding with only a $600 \mathrm{~m}$ deep convective boundary layer capped by a thin inversion layer with a $3 \mathrm{~K}$ jump in temperature. Above this is a $1,300 \mathrm{~m}$ deep neutrally stratified layer that is likely the mixed layer of the previous day. The humidity mixing ratio is constant throughout this layer and $\mathrm{O}_{3}$ is constant over the top $800 \mathrm{~m}$ of this layer. At the top of this layer is another thin inversion layer with $9 \mathrm{~K}$ jump in temperature. Within this thin inversion layer, the $\mathrm{O}_{3}$ concentration drops from about $80 \mathrm{ppb}$ to $50 \mathrm{ppb}$ and then increases above this layer to about 65 $\mathrm{ppb}$. The rather high value of $80-85 \mathrm{ppb}$ in the old mixed layer is not unusual for polluted air in this part of the country. The somewhat lower value of $65-75 \mathrm{ppb}$ in the new mixed layer may be the result of destruction of $\mathrm{O}_{3}$ at the surface during the night and possibly injection of NO (which removes $\mathrm{O}_{3}$ by chemical reaction) from anthropogenic activities. However, the sharp minimum at the top of the old mixed layer is more puzzling. This is not strictly a local perturbation since another sounding several kilometers away was very similar.

The lower set in Fig. 4 is at mid-day on the following day over south-central Nebraska, with a convectively-mixed layer about $1 \mathrm{~km}$ deep capped by an inversion layer with a temperature rise of about $11 \mathrm{~K}$. In this case we again have a well-mixed humidity and ozone profile throughout the boundary layer. In the capping inversion layer, however, the humidity decreases throughout the layer, while $\mathrm{O}_{3}$ increases from about $53 \mathrm{ppb}$ to a sharp maximum of about $95 \mathrm{ppb}$ near the top of the inversion layer and then decreases to a nearly constant value of about $72 \mathrm{ppb}$.

These narrow laminae seem difficult to explain from a purely meteorological viewpoint. We can estimate the time required for an infinitesimally thin layer of $\mathrm{O}_{3}$ to diffuse to the observed thickness in order to estimate the age of such a layer if it has evolved solely by turbulent diffusion. Lilly et al. (1974) derive an expression for the vertical eddy diffusivity of heat in a stably stratified layer,

$$
K_{H}=\frac{\varepsilon_{i}}{3 N^{2}},
$$

where $N$ is the Brunt-Väisälä frequency

$$
N^{2}=\frac{g}{\bar{\theta}_{v}} \frac{\partial \bar{\theta}_{v}}{\partial z} .
$$

Fig. 4 shows a profile of vertical velocity variance $\overline{w^{\prime 2}}$ which has been high-pass filtered with a $0.5 \mathrm{~Hz}$ cutoff filter. The turbulence dissipation can be estimated by integrating the vertical velocity spectrum using the Kolmogorov inertial subrange hypothesis

$$
E(k)=a \varepsilon^{2 / 3} k^{-5 / 3},
$$

where $a \simeq 0.68$ for the vertical wind component, to relate the energy dissipation to the variance

$$
\overline{w^{\prime 2}\left(k_{c}\right)}=\int_{k_{c}}^{\infty} E(k) d k=\frac{3}{2} a \varepsilon^{2 / 3} k_{c}{ }^{-2 / 3},
$$

where $k_{c}$ is the cutoff wavenumber approximately equal to $4.8 \times 10^{-2} \mathrm{rad} \mathrm{m}^{-1}$ for the variance profile in Fig. 4. Jensen and Lenschow (1978) have shown that vertical velocity spectra follow the $-5 / 3$ power law for wavenumbers this small in the inversion layer capping the convective boundary layer. Solving (23) for $\varepsilon$ and substituting into (20), we have

$$
K_{H}=\frac{0.32 k_{c}\left[\overline{w^{\prime 2}\left(k_{c}\right)}\right]^{3 / 2}}{N^{2}}
$$

If we now assume that the laminae were initially infinitesimally thin layers of high (or low) concentration with respect to the surrounding air and that the ozone diffusivity is the same as that for heat, we can calculate the time required to diffuse to the observed thickness. A solution for the diffusion equation with this initial condition is given by (e.g., Eckart and Drake, 1959)

$$
\bar{s}(z, t) \propto \frac{1}{2 \sqrt{\pi K_{H}}} \exp \left\{\left(z-z_{1}\right)^{2} /\left(4 K_{H} t\right)\right\},
$$

where $\bar{s}(z, t)$ is the distribution of the diffusing laminae and $z_{1}$ is the height of the center of the laminae. We define $l$ to be the thickness of the layer in which the concentration has changed from the adjacent layers by more than $10 \%$ of the maximum (or minimum) $\mathrm{O}_{3}$ concentration. For these cases, $l \sim 60 \mathrm{~m}$. With this condition, the exponent of (25) becomes

$$
\frac{(l / 2)^{2}}{4 K_{H} \tau}=2.30 \text {. }
$$

Solving for the time required to diffuse to this thickness, and substituting (24) into (26),

$$
\tau=\frac{0.084 l^{2} N^{2}}{k_{c}{\overline{w^{\prime 2}}\left(k_{c}\right)}^{2}} .
$$

For the morning case, $N^{2} \simeq 1.3 \times 10^{-3} \mathrm{~s}^{-2}$ and 
$\overline{w^{\prime 2}\left(k_{c}\right)} \simeq 0.0045 \mathrm{~m}^{2} \mathrm{~s}^{-2}$ which gives $K_{H} \simeq 3.6 \times 10^{-3}$ $\mathrm{m}^{2} \mathrm{~s}^{-1}$ and $\tau \simeq 7.5$ hours. For the noon case, $N^{2} \simeq$ $2.8 \times 10^{-3} \mathrm{~m}^{2} \mathrm{~s}^{-1}$ and $\overline{w^{\prime 2}\left(k_{c}\right)} \simeq 0.0042$ which gives $K_{H} \simeq 2.8 \times 10^{-3} \mathrm{~m}^{2} \mathrm{~s}^{-1}$ and $\tau \simeq 9.5$ hours. These diffusion time estimates do not take into account the fact that the laminae were initially probably not infinitesimally thin which would shorten the actual diffusion times. On the other hand, the layers may be diverging, which would lengthen the diffusion times.

Although there may be some question as to the accuracy of the estimated diffusion time, we can conclude that the layers are difficult to explain meteorologically since they could not have existed for more than a fraction of a day. Injection of air from smokestacks or an urban plume directly up to these levels and subsequent horizontal advection of the modified layer seems unlikely because of the buoyant energy required to lift the air 1.5 to $2 \mathrm{~km}$ and overcome a 6 to $10 \mathrm{~K}$ potential temperature rise. These layers are, however, an interface between unpolluted air in the free atmosphere and polluted boundary layer air. Mixing is occurring in this layer between these two separate air masses. One conjecture is that chemical reactions are occurring in this interfacial layer that are removing or producing ozone. If this is the case, evaluating the ozone budget in the boundary layer may, in some situations, be more complicated than previously thought. On the other hand, if these processes can be understood, they may be useful in studying diffusion into and out of the boundary layer.

\section{Concluding remarks}

Chemical reactions in trace atmospheric constituents in the boundary layer can affect both the mean and turbulent structure of the boundary layer. If the reactions occur on a time scale of a few minutes, the reaction time is comparable to the characteristic time for a constituent to diffuse from the surface through most of the surface layer or from a localized source out to scales important for turbulent transport. Thus, we can expect that surface layer profiles and turbulence structure of some reactive species that have sources or sinks at the surface may be modified from the forms predicted by similarity theory for surface and mixed layers. It may be possible to utilize these departures from similarity to estimate covariances of reactive species, which, in turn, may be useful in determining sources and sinks of these species.

Anomalously high and low values of ozone concentration in the turbulence inversion layer at the top of the boundary layer suggest that chemical reactions on a time scale of several hours may also have significant effects on boundary layer profiles. These profiles cannot be explained by simple mixing of two air masses with different concentrations of $\mathrm{O}_{3}, \mathrm{NO}$ and $\mathrm{NO}_{2}$; it is likely that other reactions are occurring as well. With appropriate measurements and interpretation, this information may also be useful in delineating important chemical reactions.

Anthropogenic activities continue to increase the burden that the atmosphere must absorb. At the same time, we are becoming more aware of and sensitive to the problems that this can engender on a local as well as global scale. Thus, understanding the cycles of trace constituents in the atmosphere is becoming of increasing interest and importance.: The problems are difficult and require a variety of tools for solution. One of these tools is the application of micrometeorological techniques to the study of trace constituents in the boundary layer

\section{Acknowledgements}

Development of the fast-response ozone sensor and its use in the field for the cases discussed here was carried out by R. Pearson, Jr. B. B. Stankov carried out the data analysis for these cases. I am indebted to L. Kristensen for discussion of some of the ideas presented here and to $\mathrm{H}$. Howard for typing the manuscript.

\section{References}

Businger, J. A., 1973: Turbulent transfer in the atmospheric surface layer, Workshop on Micrometeorology, D. A. Haugen Editor, American Meteorological Society, Boston, MA, 392 pp.

Chameides, W. L. and D. H. Stedman, 1977: Tropospheric ozone: coupling transport and photochemistry, J. Geophys. 'Res., 82, 1787-1984.

Chameides, W. L., 1978: 'The effects of increased $\mathrm{CO}$ and NOx upon tropospheric $\mathrm{OH}, \mathrm{CH}_{4}$, and related species. NASA reference Publication 1022, Man's Impact on the Troposphere, J.S. Levine and D. R. Schryer, Editors. NASA Langley Research Center, Hampton, VA, 23665, $372 \mathrm{pp}$.

Champagne, F. H., C. A. Friehe, J.C. LaRue and J. C. Wyngaard, 1977: Flux measurements, flux estimation techniques, and fine scale turbulence measurements in the unstable surface layer over land, J. Atmos. Sci., 34, 515-530.

Dobson, F., L. Hasse and R. Davis, 1980: Air-sea Interaction Instruments and Methods, Plenum Press, $801 \mathrm{pp}$. 
Eckert, E. R. and R. M. Drake, 1959: Heat and Mass Transfer, McGraw-Hill, 530 pp.

Jensen, N. O. and D. H. Lenschow, 1978: An observational investigation of penetrative convection, J. Atmos. Sci., 35, 1924-1933.

Kaimal, J. C., J.C. Wyngaard, D. A. Haugen, O. R. Coté, Y. Izumi, S. J. Caughey and C. J. Readings, 1976: Turbulence structure in the convective boundary layer, J. Atmos. Sci., 33, 2152-2169.

Lamb, R. G. and D. R. Durran, 1978: Eddy diffusivities derived from a numerical model of the convective planetary boundary layer, Il Nuovo Cimento, 1, 1-17.

Leighton, P. A., 1961: Photochemistry of Air Pollution, Academic Press, New York, 300 pp.

Lenschow, D. H., A. C. Delany, B. B. Stankov and D. H. Stedman, 1980a: Airborne measurements of the vertical flux of ozone in the boundary layer, Boundary-Layer Meteorol., 19, 249-265.

Lenschow, D. H., J. C. Wyngaard and W. T. Pennell, 1980b: Mean-field and second-moment budgets in a baroclinic, convective boundary layer. $J$. Atmos. Sci., 37, 1313-1326.

Lenschow, D. H., R. Pearson, Jr. and B. B. Stankov, 1981: Estimating the ozone budget in the boundary layer by use of aircraft measurements of ozone eddy flux and mean concentration. $J$.
Geophys. Res., 86, 7291-7297.

Lilly, D. K., D. E. Waco and S. I. Adelfang, 1974: Stratospheric mixing estimated from high-altitude turbulence measurements, J. Appl. Meteorol., 13, 488-493.

Pearson, R., Jr., and D. H. Stedman, 1980: Instrumentation for fast response ozone measurements from aircraft, Atmospheric Technology, 12, National Center for Atmospheric Research, Boulder, Colo.

Van Dop, H., R. Guicherit and R. W. Lanting, 1977: Some measurements of the vertical distribution of ozone in the atmospheric boundary layer, Atmospheric Environment, 11, 65-71.

Wyngaard, J. C. and M. A. LeMone, 1980: Behavior of the refractive index structure parameter in the entraining convective boundary layer, $J$. Atmos. Sci., 37, 1573-1585.

Wyngaard, J.C. and O. R. Coté, 1971: The budgets of turbulent kinetic energy and temperature variance in the atmospheric surface layer, J. Atmos. Sci., 28, 190-201.

Wyngaard, J. C., O. R. Coté and Y. Izumi, 1971: Local free convection, similarity, and the budgets of shear stress and heat flux, J. Atmos. Sci., 28, $1171-1182$.

\title{
微気象学的にみた境界層中の反応性微量成分の挙動
}

\author{
D. H. Lenschow \\ National Center for Atmospheric Research
}

大気境界層中に存在する反応性微量成分の平均量拉よび变動量は化学反応の影響を受けると思われる。この論 文では, これらの化学反応の影響について, 航空機に搭載した応答性の高いオン゙ン測定器による測定結果を用い て考察した。オン゙ン濃度変動を乱流量の収支式を用いて検討したところ，濃度变動に化学反応が影響していると 推定される測定例を見い出した。また，他の例では，境界層上部の乱流逆転層中で，オン゙ン濃度がその上下の層 の濃度とまったく異なる特異層となっていた。この特異層についても，その生成の要因として化学反応が最も適 当と思われる。化学反応についての時間スケールを 100 秒程度とすると, 反応性の高い微量物質の接地層内での 鉛直分布は，化学反応の影響を受けることが推定された。これらの化学反応性物質の研究は，境界層中での微量 物質の発生源や吸収源の研究に有効であると思われる。 